\title{
After Convergence: YouTube and Remix Culture
}

Anders Fagerjord, Department of Media and Communication, University of Oslo anders.fagerjord@media.uio.no

This is the preprint version of a chapter in the International Handbook of Internet Research, edited by Jeremy Hunsinger, Lisbeth Klastrup and Matthew Allen (Springer, 2009). When published, the original publication is available from

http://www.springerlink.com

\begin{abstract}
The term 'convergence' has been used to describe the media developments following digitalization. In this article, I argue that while convergence was a suitable term to describe the first developments, it is no longer fitting. Convergence levelled out the differences between media, allowing for the developments we now see, and for which I propose the term 'remix'. Using YouTube as an eample, I outline how genre developments may be seen as remixes of earlier genres, how remixing has become a widespread creative practice, and how online media also remix power relations between media owners and their audience.
\end{abstract}

\section{Beyond convergence}

In little more than a year, from November 2005 to the autumn of 2006, YouTube became a new media phenomenon. This library of videos uploaded from millions of users is one of the best examples of the complex matrix of new media that are described as convergence (Walther, 2005), convergence culture (Jenkins, 2006) and Web 2.0. (Musser and O'Reilly, 2007). It is complex because the content is unpredictable. On YouTube, there are lots of recordings from TV shows and films old and new. Amateur videos of stunts, fiction, parodies and pastiches abound. Professional recordings attempt to market products and artists famous and would-be famous. Regular people put up diary-like recordings of speaking into a camera. Politicians cry for attention in more or less convincing talks, "viral marketing" try to disguise its commercial message, and fictional diaries pretend to be real. And the declining genre of the music video has found 
a new life online (Austerlitz, 2007). YouTube is not just a web phenomenon; it is in open contest with broadcast TV. Not only does TV shows look to YouTube for newsworthy or entertaining material; As MediaCenter PCs and AppleTVs occupy the place of the TV set, and mobile phones are ready to show you YouTube videos wherever you are, YouTube promises to follow you everywhere. YouTube seems to me to be a good example to discuss modern online media with, but first, we need to back up a little.

When Nicholas Negroponte resigned from his column in Wired Magazine in 1998, he had written for six years about new media technology, and his ideas of what the future will bring. Most of Negroponte's influential book Being Digital (Negroponte, 1995) originated in the column in Wired. But in 1998, it seemed that his crystal ball became clouded. He could no longer write about the changes that would come with the digital future, as the future had arrived. "The digital revolution is over," he wrote in his final column (Negroponte, 1998).

From the late 1970ies, mass media became digital. The effects of this digitization has often been described as convergence, the coming together of the media. Media converged in different ways as most media could be represented as numbers on a computer:

Production tools converged. Computers were increasingly used to create and edit text, images, sound, film, and television images. A large array of different media technologies was replaced by software on powerful computers.

Distribution networks converged. All kinds of networks could carry the digital signals representing various media forms. Telephone wires, television cable networks, computer networks, and wireless telephone networks were all able transmit telephony, television, and internet traffic of all kinds.

Business sectors converged. Before digitization, the computer industry, the publishing industry, the telephone industry, the film industry, the music industry, and the broadcasting industry were thought of as separate business sectors. Owners of telephone and TV cable networks soon realised, however, that they had become competitors in the business of carrying all kinds of digital 
signals. News corporations realised that they could also produce radio and television on the computers they had bought for newspaper production. Radical mergers and acquisitions followed, the most spectacular being the combination of Netscape, America Online, Time and Warner culminating in the huge conglomerate AOL Time Warner in 2001.

Genres and services converged. Web sites provided stories and information in video and sound as well as writing and images, with links to pages where consumers could shop, reserve tickets, do their banking, or file tax forms.

The technologies used by consumers, such as television sets, telephones, newspapers, video recorders, DVD players, game consoles, and computers converged. As I am writing this, the computer and mobile phone manufacturers are competing in making computers and mobile phones that will replace the last traditional TV sets, radios, and telephones in our homes with computers that are dressed up to look good in the living room, while they basically have the same chips and software inside as the computers used to create the TV and radio shows.

Nicholas Negroponte was one of the first to recognise this development, and he may have been one of the first to use the term convergence to describe it. ${ }^{i}$ During the 1990ies, business leaders, politicians and journalists discovered that convergence was a concept that could explain in a very precise manner the huge changes in the media businesses. I will argue, however, that convergence is over. The media have already converged. And again, Negroponte may have been one of the first to realise it: "We are now in a digital age" (Negroponte, 1998).

Convergence as a development must logically end at some point. Either because media cease to converge, or because all media have converged into one, or have reached a limit where further convergence is impossible. In theory, it could continue until we only had one kind of technology (a computer), using only one kind of network, to project one combined genre from one single company. It doesn't seem very likely or desirable, though. Although many have 
predicted massive merges of media companies, it is likely that markets will consolidate with a number of actors. Most countries' legislators also wish for competition between media houses. There has furthermore become much easier to start up a new media company, as there is no need for large investments in technology for production and distribution. Alongside the market convergence into a small number of media conglomerates, we see an explosion in small niche products, divergence.

Perhaps the easiest way to see that convergence is a description with limits is to consider the offering of digital devices. Far from seeing a digital "über-box", a media machine to replace all known media, we are witnessing an explosion of different digital music players, game consoles, video recorders, GPS systems, personal digital assistants, cameras, and mobile phones; and combinations of any number of such devices. In 2007, Apple's iPhone created an enormous buzz. The little black glass and aluminium-convered slab seemed once again to promise to have everything in a small package. A few years earlier, Sony's PlayStation Portable claimed the same. I own both, and as Walther (2005) observes, they have different essential functions. Both are video and music players, but the PSP is a game console, and the iPhone is a phone. After a decade or mor of convergence, I certainly do not have any fewer devices now than I had ten years ago, and the owners of my local electronics store are pleased.

The basics of capitalism dictates that technology companies will continue to invent new gadgets for us to buy, and media "content providers" will continue to create messages in many forms. ${ }^{\text {ii }}$ As the idea of total convergence is absurd, we need to ask ourselves when the new developments in the media cannot be explained by the mechanics of convergence anymore. I believe that we are beyond that point. Henry Jenkins, one of those best who understands the mechanics of convergence, admits that "we are not yet ready to cope with its complexities and contradictions" (Jenkins, 2006). My suggestion is to look for other concepts than 'convergence' to describe internet phenomena. We can direct our focus in other directions by adopting a new vocabulary. 
The concept of convergence is stretched beyond what is meaningful. Several researchers have registered that rather than converging into fewer technologies, companies, or genres, we are witnessing a proliferation of media; a divergence (cf. (Bolter \& Grusin, 1999; Fagerjord, 2003b; Liestøl, 2006; Manovich, 2001; Walther, 2005). Some, like Bo Kampmann Walther (2005) or Jenkins (2006) want to subsume divergence under convergence, as they are part of the same development: the consequences of digitalization. I think, however that we are able to be more specific, at least in the study of genres and forms of expression. Instead of just noting that their number is increasing, I would like to understand how new forms are developing online. To gain such and understanding, we need to start somewhere, so I will venture a new term to describe what has been going on the last few years: remix.

\section{What comes after convergence? Remix}

My claim, for the time being, is that remix is what comes after convergence. Convergence is the process of levelling the differences between the different media. Digital representation has become a lingua franca; it has created a shared space where forms from different genres in different media may be combined in new ways, creating new genres. I have characterised this process earlier as a "rhetorical convergence" (Fagerjord, 2003a, 2003b). In the present essay, I will propose the term remix to characterise how rhetorical convergence is created. This is only a subtle difference, but by using remix I hope to change the focus away from an understanding of media development as convergence, as indicated above.

As we will see, I am not the first to use this word. Lawrence Lessig (2007) has described modern folk culture as a "remix" culture or a "read/write" culture. Millions of people with inexpensive computers copy and paste elements from digital mass culture, and assemble them into new works. (Jenkins (2006) uses the term Convergence Culture for the very same phenomenon.) I will use the 
concept in a similar way, trying to show that it is a fitting description for many phenomena in the age of YouTube.

In music, to remix is to create a new version of a recording by altering the mix of the different musical elements, or also to introduce new elements. Some remix artists create completely new pieces by combining elements of different recordings. In what follows, I would like to point out that this is quite parallel to how several new media developments have come about. First, I will describe remix as a way of creating new genres from pieces of earlier genres. Then I will discuss remix as a certain mode of creativity, allowing anyone to become a media auteur. Last, I will suggest that the massive file sharing we are witnessing is part of the same development, as a remix culture is a culture of "rip and create".

\section{Remix as genre movement}

How does a new genre develop? Gunnar Liestøl argues genre development can be described as a process of convergence. Liestøl uses a maelstrom as a metaphor to explain this, referring to Poe's short story "Through the Maelstrom where a boat is chrushed in a maelstrom, and the protagonist only survives by clinging to the debris. "When water runs through a narrow sound, strong forces are created, forces that may rip apart a boat that follows the current. The debris - the separate parts of the boat-may be reassembled in new ways afterwards; as a raft in Poe's example (Liestøl, 2007, Forthcoming).

In the same way, digitalization makes it possible for us to reassemble parts from earlier media, such as writing and moving images. Or writing and live broadcast. Telephony and photography in the same device. These are developments that have been called examples of convergence. But the figure of convergence breaks down as soon as we realise that there are no end to the creation of new such combinations. This is why I believe remix is a better word.

When genres are remixed into new, parts from different media and different technology are often spliced together. This may be difficult to realize, as technologies, media, and dominating genres have been so closely knit together 
that it has been difficult to separate them, even in theory. A medium is more than the technological apparatus that transmits signs from one place from another. In addition to technology, each medium is characterized by a certain form of financing, legal status, social conventions, and dominant genresiii (see Williams, 1975 for discussion of how television became the medium it is today). Genres are families of texts, families that share important aspects such as a certain kind of story, a certain style, or a certain subject matter. These three levels are independent. A technology may be used by several media: a printshop can print both books and newspapers. A genre may exist across several media, as detective stories exist in print, film and on television.

These distinctions become blurry on the Web. It is possible to film children swimming for 10 minutes and show the film in a cinema theatre, but the cinema institution is built up around a spectacular feature of 90 minutes. Family shots are the domain of video. On the Web, on the other hand, family clips, TV news and feature films may be part of the same web page-and sometimes are. And from such mixes, new genres may develop.

Let's look at a popular concept of convergence: the convergence of television and print newspapers. It is a simple idea that has inspired many mergers of television and print companies worldwide. So what does the combination of paper and telly look like? It is immediately clear that it has many different looks already, and more are likely to come. Many online versions of print newspapers offer video as illustrations to their stories; a short video clip is inserted in the page where a photo normally would be. Other web news sites keep the videos in a dedicated window, a "media player," where a selection of video clips are available from a menu, rather independent of the written news of the day. A third way of converging, however, is not to borrow the moving image of television, but rather its liveness, the very trait that many theorists consider to be television's most defining characteristic (Eco, 1999; Feuer, 1983; Heath, 1990). A web news site is live in the same manner as broadcasting, in that it may distribute its stories as soon they are ready, or even as the events unfold. Sports 
events are often covered live in writing: A reporter is watching a football match, for example, and typing a written description of the action that is published one line at a time. Some times, these reports are even mirrored on the news site's front page, so it is continually updated: a live front page.

Genres may form in many ways. Media and genres are combinations of many characteristics, that traditionally have occurred in stable combinations: Moving images + address to camera + documentary footage + live broadcast + regular schedule + many short segments presented in a sequence for 20 minutes $=$ television news.

On the Web, each of these characteristics, each of the variables in this equation, may be mixed into a new genre in remix culture. For example: Moving image + address to camera + documentary footage + recorded broadcast + irregular schedule + many short segments available for selection by user + written comments by viewers $=$ video blog.

I believe the present media developments may effectively be likened to the children's game where cardboard figures of people in different costumes, such as a fireman, a baker, a policeman, a painter, a pirate, Santa Claus, etc., are cut up so the hats, faces, torsos, and legs may be mixed to create new figures. To understand remix culture, we need to understand where the "media figures" are cut, so to speak: We need to isolate the aspects of genres that may be remixed into new genres and media configurations.

\section{What parts are mixed?}

In an earlier study of convergence in documentary sites on the web, I identified four variables of texts that may be changed independently in digital genre remix (Fagerjord, 2003a). The four "axes," as I termed them, are:

Sign system: the choice of writing, images, sound, video, etc. Earlier media had choices of sign system; a book cannot contain video. In digital media, the 
author may use a different sign system or combination of sign systems in every text.

Mode of Acquisition: the "reading" process required of the audience. A movie in a movie theatre is consumed from start to finish without interruptions, while a book may be read in many long or short sittings, and parts may be reread or skipped. Digital media also often offer hyperlinks, allowing each audience member to decide the sequence of the parts. The mode of Acquisition is changed radically, for example, when a film is made into a computer game.

Canvas: the size and resolution of the text in time and space. A movie clip on YouTube is very different from the viewing experience of the whole feature in a theatre. The YouTube clip is shorter, much smaller, and with way inferior sound and image quality. The canvas is limited by technology, as in the YouTube example, but also chosen by the author to suit her or his intended audience. It is possible to distribute video in High Definition quality on the web, (Apple computers regularly does this), but most web authors consider such a quality to require too much bandwidth. Similarly, most film directors and producers keep movies within two hours, or three at the most. There is a limit to how long most audience members are willing to stay in the theatre seat. DVD versions of the same films may be longer, however, as they are watched in the comfort of one's home - the Lord of the Rings trilogy directed by Peter Jackson is a case in point.

Distribution: the time it takes to create a text, to distribute it to the readers, and how long the text stays available. For a live broadcast, creation and distribution time (or latency) are close to zero, and the text is gone when the broadcast is over (zero permanence). A regular newspaper may take several days to prepare, a night to print and distribute, and the readers may keep it for as long as they please, for most people a few days. Digital genres may remix these variables. A live video broadcast may be available as a recording for years, for example.

While I believe sign system, acquisition, canvas, and distribution are four variables that may be useful in describing any genre; they are the result of a 
study of the documentary genre. If our ambition is to describe other genres too, we will need additional aspects. If we are to describe the genre conventions and experimenting we can see on YouTube, for example, we will need some extra variables in our description.

First of all, the principal distinction that sets the genres of documentary and the feature apart from other genres is the text's relation to reality. A documentary film is made primarily from non-fiction photographic footage. News is another genre that rests upon the idea that its are real, relatively objective, and true ${ }^{i v}$. A genre's relation to reality is another aspect that may be remixed. First, we need to remember that the distinction of fiction/non-fiction is a continuum, not a dichotomy. If we take movies as an example, one can list many fiction films about real events (e.g., Titanic, JFK, Amadeus), but also documentaries with elements of fictionv (Roger and Me, Creature Comfort, ThirtyTwo Short Films About Glenn Gould) as well as fiction guised as documentary (This is Spinal Tap!, The Blair Witch Project). By paying attention to how a text uses fictional elements, we can often reveal mixing of genres.

The blurring of the border between fiction and non-fiction is, as these examples from cinema show, not necessarily a development that is caused by digitalization. It is quite common online, however, perhaps because the web is a place where anyone can publish at low cost, so it is affordable to experiment. One of the most common forms of genre remix on the web is to use the formal characteristics of news or documentary, but with a different relation to fiction. Blogs are examples of a genre which owns much of its layout to newspaper design, but where the writing has little in common with newspaper reporting. Web logs are generally written in a personal voice, and many blogs contain fictitious material. Furthermore, on the web, where genres constantly are remixed and redeveloped, much debate is caused from precisely the tension between fact and fiction. Thousands of fans were deeply disappointed when it was revealed that the home schooled teenager Bree in the video blog Lonelygirl15 (Lonelygirl15, 2007) were characters of fiction, and John Richardson's long piece 
in Esquire of the search for the blogger Isabella V. of She's a Flight Risk, is a document of the same urge to know whether a story is for real (Richardson, 2003).

Anonymity and posing has been a characteristic of digital culture at least since the era of e-mail lists, bulletin board systems and Usenet news groups, long before the commercial internet and the web. Researchers have devoted much interest to members of discussion groups, chat rooms, and multiplayer games that have posed online as a different gender and age, as well as robotic characters, computer programs posing as players or discussants (see, among others, (Aarseth, 1997; Murray, 1997)). The famous cartoon from The New Yorker sums it up: a dog is typing at a computer keyboard, noting to another dog: "on the net, nobody knows you're a dog. ${ }^{\mathrm{vi}^{1}}$ Again, the questions of fiction or real is not necessarily caused by, or even a part of the digital revolution, but in a postconvergence age where remix is the norm, reality and fiction is often both mixed and remixed in new genre developments.

Another important aspect of every genre is purpose, the rationale behind the text's creation and its place in the lives of the audience, what we might call its "social function." Media scholars within the tradition of Cultural Studies have discussed the functions of different media genres for decades (see, e.g., (Barthes, 1972; Fiske, 1987; Fiske \& Hartley, 1978; Hartley, 1982, 1999; Morley \& Brunsdon, 1999; Radway, 1984). We may read the newspaper to be informed, to keep up with the important people in the world (Fiske (Fiske, 1987) describes news as men's soap opera), and to check that the world still is as we know it. A television sitcom may be a welcome pleasure helping us to relax after a day's work (cf. (Adorno \& Horkheimer, 1999), at the same time confirming our beliefs and ideologies. Charles Cheung is one of many who have noted that the web has allowed ordinary people to publish web sites about themselves, thus defining and reworking their identities (Cheung, 2004). Not that it is novel to write to define one's identity, Michel Foucault has noted how people have "written their 
selves" for centuries (Foucault, 1994), but on the web, this is often a public activity.

It is possible to use formal aspects of some genres and mix with the purpose of another. A blog might, for example, be called a remix of a web news site and a diary. Both news sites and blogs usually have a front page with the most recent items, presented with short leads or excerpts from the full article. The full article is linked from the front page. Articles are posted every week or every day, which means that the front page is regularly changed. But most blogs differ very much from news sites in terms of topic, tone, and subjectivity. Lonleygirl15's mix of reality and fiction is also a mix of formal aspects from one genre with the social purpose of another. What appeared to be a typical journallike confessional video blog, was shown to be fiction. Instead of being a selfdefining exercise, where Bree was taking part of an online social network, it became a narrative, where a story from Bree's life was told in the first person, addressing the camera, affording the pleasures of narrative to its audience.

Although it is customary to speak of weblogs as a somewhat unified genre, it is obvious to anyone that there is enormous variation between blogs. If we speak of blogs as a unified class of web sites, what unites them is their publishing technology. Weblogs tend to be served by database-backed systems allowing for quick writing and publishing, archives of older posts, easy linking, systems for user comments, link lists, and various other automatic indexing services. This technical apparatus is used to host sites that serve very different purposes. The technology that serves many a teenager's journal is also used to publish the stylish metropolitan news site Gothamist, the home page of the Creative Commons movement (working to establish an alternative to copyright), and the home page for the developers of the web browser Apple is using.vii Many of the genre characteristics of blogs are pre-scribed by the publishing system, so these sites look quite similar, although their aims differ. 


\section{Remix as a mode of creativity}

Remix is not only a helpful concept in understanding how new genres form, it does also seem to be a common technique to create new works. The many videos on YouTube demonstrate this.

YouTube is a remix in itself: While it would be a stretch to call YouTube an example of convergence, you might call the site a clever remix of a video gallery, a blog-like commenting system, a system of friends and connections as in a social network site such as LinkedIn, and a file-sharing site or network. The key to the site's success, however, is how easy it is to upload video. Any kind of video is automatically transcoded to Flash, a file format most web browsers can play back without extra installations. Each video is hosted on its own address (URI), that may be bookmarked or e-mailed, and YouTube is also automatically producing HTML code that users can copy and paste to include video in their own web pages. These functions have made it so easy to share video on YouTube that in early 2007, 65, 000 new videos were uploaded, and 100,000,000 clips viewed each day, according to the company's web site (YouTube, 2007). Anyone who spends a couple of hours browsing the strange collection will realize that a large proportion of these clips may be characterized as remixes in one way or another. viii

In his account of computers as a medium for artists, Lev Manovich has called creativity as selection and compositing two of the "basic operations" of computer software (Manovich, 2001) pp. 120;123-41). Software applications for design and creativity tend to offer menus of choices for the creator. Manovich's examples include textures and human figures in a 3D animation program, filters in an image editor, libraries of computer code in a programming environment, and clip art images in a home page editor on the web. "New media objects are rarely created completely from scratch; usually they are assembled from readymade parts. Put differently, in computer culture, authentic creation has been replaced by selection from a menu" (p. 124). Whether "authentic creation" has 
ever been free of combining new elements with copies or pastiches of earlier work is not a discussion I want to open in this article (Manovich does that himself a few pages later) but it certainly has become much faster and easier to combine ready-made parts with computer software, and that it often requires no other training than being able to use a computer interface.

Selection goes hand in hand with the other operation, compositing; the creation of images from many transparent layers, Manovich notes. The contents of each layers may come from many different sources, and "are fitted together and adjusted in such a way that their separate identities become invisible" (Manovich, 2001) p.136). Manovich only discusses still images and individual shots in film in his section on compositing. This is less common in amateur videos on YouTube, apart from superimposing (written) titles and adding a sound track. Compositing software, and especially effacing the traces of the compositing is still the work of professionals. What is much more common is to composite in time; to edit together images from different sources to make a clip. ${ }^{\text {ix }}$

It is not uncommon to find videos on YouTube that make an argument; often a political statement. ${ }^{\times}$These tend to be collages of television footage, photographs, written documents, and explanatory text or voice-over narration. Elements taken from a wide variety of sources are mounted together to a coherent message, trying to get a point through. More often than not, the images and video clips are used against their original purpose; a politician's statement may, for example, be used to show that he is wrong. Imagery, sound and text are remixed into a new whole, following the logics of selection and compositing. Creativity by selection is also apparent in another genre found on YouTube: slideshows made of still images, most often images of celebrities taken from magazines. In a typical slideshow, a series of images are selected from a source, and then put in a sequence. Using a video editing program, the creator selects different ways of moving the frame over the still images, and transitions between them. A soundtrack is created by selecting a piece of music from a collection, and 
a few lines of text are perhaps added, again by selecting text effects from a menuxi.

Each user's "channel", that is, the web page with all of his or her YouTube videos may be personalised somewhat. Selecting from menus, the user may change colours and some of the elements on the page in an attempt to personalise his or her space. This use of templates is typical in most of digital creation, especially by amateurs, and is another example of creativity by selection. A template is a "half-baked" work, where some of the elements already are created. The user can fill in his or her detail, and the finished work is created faster, and often better, than it otherwise would be. ${ }^{x i i}$ Media creation by templates is another example of creativity by selection, a kind of creativity that is widespread in digital media. Pre-existing elements are inserted into a preexisting template, and remixed into a new work, rather like a DJ is mixing music. As Manovich puts it: "The DJ best demonstrates [computer culture's] new logic: selection and combination of preexistent elements. [...] [T] he practice of live electronic music demonstrates that true art lies in the 'mix'" (p. 135).

\section{Rip and remix culture}

The most popular videos on YouTube each day seem to be rips rather than remixes. Clips from television shows, music videos, film trailers, and other short and self-contained scenes from television and film are recorded, digitized, edited in the beginning and end, and uploaded to YouTube. In short, "ripped". In many cases the copyright holders do this themselves; many record companies, film distributors and television channels have "channels" on YouTube. Most television clips seem to be uploaded by regular users, however, even though YouTube is trying to weed out infringements of copyright.

Although these clips aren't remixed in any visible way, I believe it makes sense to think of them as part of the same remix culture as slideshows and other films made by pre-existing parts. 
Why are people ripping and sharing these clips? Certainly not for profit. It is sharing, not selling. In digital media, when convergence have levelled out the differences between media technologies, and copy-and-paste is the most common operation in creation, to isolate a part of a larger text and quote it is normal practice. Moreover, most television and film can't be linked. Experienced web writers are used to writing hyperlinks to all kinds of interesting material. The web is so enormous that links are some of the most important information; it is the currency of the web. Google's success is based on this: Google's search engine ranks its results based on links to the pages. The logic of the web is that everything should be linkable, and when valuable moving images aren't, then YouTube is a great way of making them available for linking.

To rip and share a clip without remixing it is in fact to state its value. It is good enough already; it doesn't need to be enhanced-at least not for the moment. The old maxim holds true on the web: "Plagiarism is the sincerest form of flattery."

A parenthesis may be allowed here: We who work in universities see another form of this rip culture in student papers. Fresh students routinely copy texts from the web, especially from Wikipedia into their own papers, without quote marks or information about the source. To suspect plagiarism and searching the web for proof has become a routine part of my job. When I point out to my students that this practise will be considered cheating, they often get confused. To copy and paste, rip and remix has become so natural to today's 20year olds in Norway today, that we have to teach them the idea that you might create your own sentences.

I will return to my main argument to point out that the culture of remixing also has made people feel the need for copyright reform. The most marked example of this in recent years has been the Creative Commons, an organisation arguing that creators should mark their works with a licence allowing others to use their work to create new works. The Creative Commons have made the text of several such licences available, making it easy for authors 
to retain their authorial rights while allowing others to cite and remix (see Lessig, 2001 for a legal discussion of these principles).

\section{Remix of Power: Who Gets to the Podium}

While there is a lot of rips and remixes, my impression is that most videos on YouTube are people filming themselves. They put up a camera and talk to it, or perform in front of it, often in silly ways. Before video sites like YouTube, films of this kind were shared among friends and shown in the living room, if they were made at all. YouTube has provided a platform for people where they can share these performances with the whole wired world. Everyone can become a broadcaster. The digitalization has brought about a total remix of power relations. Two decades ago, mass media were for the few and wealthy. To create a newspaper or a broadcasting operation required large investments, and for television, you would in most countries also need a licence. Web-based creation services such as blogs and YouTube have created the possibility for anyone to run his or her own mass medium (without any guarantees for an audience, though). What has happened when this power was delegated was that most people who take this opportunity use it to perform themselves or their selves, as previously noted.

And this brings us full circle back to the remixing of genres. The digital remix of power relations have opened the gates to people with other purposes than to attract large audiences for public debate or commercials. Elements known from broadcasting and the printing press are remixed with elements of diaries, of private conversations, of local theatre and concerts, and many others.

\section{Remix and Creation}

This paper is about media development in the decades after digitization. I have argued that while convergence was a useful term for the first developments, it is no longer helpful in understanding developments in the media. The phase of convergence was the process of introducing digital technologies in all kinds of 
media production, and thus changing the technological differences between them. Digitalization levelled out the differences, allowing elements earlier known from one medium to be adapted into another.

It is this process of borrowing and adapting between media and genres that I have tried to describe as remix. The problem with any term to describe or even explain developments is that it easily may be taken to account for more than what was meant. I do not wish to say that remixing is caused by digitalization. There has of course been remixing going on earlier. We see remixing in music and film before computers entered the editing process. Creative development is often exactly to combine earlier material. Remix may be an ill-chosen term for this reason (although not any worse than convergence. Could not a 1980ies portable cassette radio player be described as a result of the convergence of the radio and the cassette recorder?). I hope to make clear, however, that while remix is one of the oldest forms of creativity, it has become much more widespread in the digital age. What digitalization did was to make this kind of creation much simpler.

Digitalization has levelled the technological differences between media, so remixing of genres is much easier. Any aspects of any genres may be constantly be recombined into new genres and services.

Digital data may be copied without loss of quality, so it has become much easier for anyone to remix, recombine, and create new dependent works.

Template-based tools provide ready-made scaffolding for new works. And as the digital network reaches anyone, the power relations have also been remixed, allowing anyone to be a creator, publisher, or broadcaster-or prod-user, as Axel Bruns calls it in his article in this volume.

Novelist William Gibson, the man who coined the term cyberspace, put it this way in Wired in July, 2005:

Our culture no longer bothers to use words like appropriation or borrowing to describe those very activities. Today's audience isn't listening at all - it's 
participating. Indeed, audience is as antique a term as record, the one archaically passive, the other archaically physical. The record, not the remix, is the anomaly today. The remix is the very nature of the digital. (Gibson, 2005)

Aarseth, E. J. (1997). Cybertext: Perspectives on Ergodic Literature. Baltimore: Johns Hopkins University Press.

Adorno, T. W., \& Horkheimer, M. (1999). The Culture Industry: Enlightenment as Mass Deception. In Dialectic of the Enlightenment (pp. 120-167). London: Verso.

Austerlitz, S. (2007). Money for Nothing: A History of Music Video from Beatles to the White Stripes. New York, Continuum.

Barthes, R. (1972). Mythologies. New York.

Bolter, J. D., \& Grusin, R. (1999). Remediation: Understanding New Media. Cambridge, Massachusetts: MIT Press.

Brand, S. (1988). The Media Lab: Inventing the Future at MIT. New York: Penguin.

Cheung, C. (2004). Identity Construction and Self-Presentation on Personal Homepages: Emancipatory Potentials and Reality Constraints. In D. Gauntlett \& R. Horsley (Eds.), Web.Studies (Second ed., pp. 53-68). London: Arnold.

Eco, U. (1999). Kant and the Platypus: Essays on Language and Cognition. London: Secker \& Warburg.

Fagerjord, A. (2002). Reading-View(s)ing the Über-Box: A Critical View on a Popular Prediction. In M. Eskelinen \& R. Koskimaa (Eds.), Cybertext Yearbook 2001 (pp. 99-110). Jyväskylä: Publications of the Research Centre for Contemporary Culture.

Fagerjord, A. (2003a). Four Axes of Rhetorical Convergence. Dichtung Digital(30). Fagerjord, A. (2003b). Rhetorical Convergence: Studying Web Media. In G. Liestøl, A. Morrison \& T. Rasmussen (Eds.), Digital Media Revisited. Cambridge: MIT Press.

Fagerjord, A. (2005). Prescripts: Authoring With Templates. Kairos, 10(1).

Fetveit, A. (2002). Multiaccentual Cinema: Between Documentary and Fiction. University of Oslo, Oslo.

Feuer, J. (1983). The Concept of 'Live Television': Ontology as Ideology. In E. A. Kaplan (Ed.), Regarding Television (pp. 12-22). Los Angeles: American Film Institute.

Fiske, J. (1987). Television culture. London: Methuen.

Fiske, J., \& Hartley, J. (1978). Reading television. London: Methuen. 
Foucault, M. (1994). Self Writing (R. Hurley, Trans.). In P. Rabinow (Ed.), Ethics (Vol. One). London: Penguin.

Gibson, W. (2005, July 2005). God's LIttle Toys. Wired, 13.

Hartley, J. (1982). Understanding news. London: Methuen.

Hartley, J. (1999). Uses of Television. London: Routledge.

Heath, S. (1990). Representing Television. In P. Mellencamp (Ed.), Logics of Television. Bloomington, Indiana: Indiana University Press.

Jenkins, H. (2006). Convergence Culture: Where Old and New Media Collide. Cambridge, Massachusetts: MIT Press.

Lessig, L. (2001). The Future of Ideas. New York: Vintage.

Lessig, L. (2007). "How Creativity is Being Strangled By the Law". TED:

Technology, Entertainment, Design. Monterey Conference Center, Monterey, TED Conferences. Video recording available at <http://www.ted.com/index.php/talks/larry_lessig_says_the_law_is_str angling_creativity.html>

Liestøl, G. (2006). Conducting Genre Convergence For Learning. Cont. Engineering Education and Lifelong Learning, 16(3/4), 255-270.

Liestøl, G. (2007). The Dynamics of Convergence and Divergence in Digital Domains. In T. Storsul \& D. Stuedahl (Eds.), The Ambivalence of Convergence. Gothenburg: Nordicom.

Lonelygirl15. (2007). Lonelygirl15.

Manovich, L. (2001). The Language of New Media. Cambridge: MIT Press. Morley, D., \& Brunsdon, C. (1999). The Nationwide Television Studies. London: Routledge.

Murray, J. (1997). Hamlet on the Holodeck: The Future of Narrative in Cyberspace. Cambridge, Massachusetts: MIT Press.

Negroponte, N. (1995). Being Digital. London: Hodder and Stoughton. Negroponte, N. (1998). Beyond Digital. Wired, 6.

Radway, J. A. (1984). Reading the Romance: Women, Patriarchy, and Popular Literature. Chapel Hill, N.C.: University of North Carolina Press.

Richardson, J. (2003). The Search for Isabella V. Esquire, 140.

Walther, B. K. (2005). Konvergens og nye medier. Århus: Academica.

Williams, R. (1975). Television: Technology and Cultural Form. New York: Schocken. YouTube, I. (2007). YouTube Fact Sheet.

i The Oxford English Dictionary has recorded the first use of convergence in this sense in 1978, while Stuart Brand reports that Negroponte used it in 1973 (Brand, 1988). 
ii I have argued this point further in an earlier essay (Fagerjord, 2002).

iii I am here using 'medium' in the sense of 'mass medium', common in media studies. Within art history, e.g.,' medium' has more the meaning of 'material'.

iv The idea of absolute truth is difficult to defend from the attacks of philosophy and poststructuralism, and much of media studies is devoted to demonstrating that news are just one account of many possible of a truth that may never be reachable. I will still argue, however, that what we regard as news is only possible if we believe them to be reasonably true-even for media professors who know that at the end of the day, they may not.

v See (Fetveit, 2002)

vivi The cartoon is by Peter Steiner, and ran in The New Yorker 5 July, 1993.

vii <http://gothamist.com>, <http://creativecommons.org>, $<$ http://webkit.org>

viii As far as I know, no one has done a statistical analysis of what Youtube's videos are about. I hope future research will give us an overview of what this cornocupia of moving images actually is full of.

ix Selection and compositing also has obvious similarities with "mashups", Web services that combine services from other Web sites, such as Google Maps or Amazon book titles with other information. See Musser and O'Reilly (2007) for a discussion of mashups.

x For example, see $<$ http://youtube.com/watch?v=J1bm2GpoFfg $>$ or $<$ http://www.youtube.com/watch?v=Sy_8THVO-1w>

xi See, for example, $<$ http://www.youtube.com/watch?v=_9BTDH2uYuk $>$ or $<$ http://www.youtube.com/watch?v=HApH_HiyK7E>

xii For a further discussion of templates see (Fagerjord, 2005). 